\title{
Behavioural deviance and maternal depressive symptoms in paediatric outpatients
}

\author{
M FITZGERALD \\ Queen Elizabeth Hospital for Children, London
}

\begin{abstract}
SUMmARY A consecutive series of 953 to 4 year old and 437 to 11 year old children attending surgical, and medical outpatient clinics was studied, using questionnaires that measured behavioural deviance and had adequate reliability and validity for screening populations of children. A control group was also studied in the 7 to 11 year old sample. Depressive symptoms in the mothers of the children were determined using the Wakefield depression inventory. There was considerable behavioural deviance in children attending the outpatient clinics; $44 \%$ of the 7 to 11 year olds who were surgical outpatients had deviant scores. Thirty two per cent of mothers of medical outpatients had deviant scores on the depression inventory. These findings have relevance for the approach paediatricians take to their outpatients.
\end{abstract}

The prevalence of behavioural deviance in children attending outpatient clinics has important implications for paediatricians in relation to the type of service that they are being asked to give and to the approach to treatment. Although there has been a great increase in our knowledge of the prevalence of behavioural deviance over the past 15 years,${ }^{1-4}$ there has been a limited amount of study of medical and surgical outpatients. The prevalence of maternal depression in a community has been studied, ${ }^{4}$ but the prevalence of depressive symptoms in mothers who bring their children to paediatric outpatients has not. In the Isle of Wight, $50 \%$ of mothers who had children with a psychiatric disorder had a psychiatric disorder themselves, namely depression, compared with $10 \%$ of mothers of normal children. An American study ${ }^{5}$ showed that $5 \%$ of patients attending paediatricians in private practice were reported to have emotional, behavioural, or school difficulties. In children with abdominal pain it has been shown that in only $7 \%$ is the cause physical. ${ }^{6}$

As has been pointed out by Howells, ${ }^{7}$ the presenting patient, in this case the child, is not necessarily the member of the family most in need of help. This clinical observation as well as epidemiological studies in child psychiatry suggest that the paediatricians should look beyond the presenting physical symptoms for evidence of child psychiatric disturbance and maternal depression.

The following hypotheses based on clinical experience were set up: (i) that there would be more behavioural deviance in the medical and surgical outpatients than in the control children in the 7 to 11 year old age group, (ii) that there would be more depressive symptoms in mothers of children attending the medical outpatient clinic than in mothers of surgical outpatients.

\section{Patients and methods}

All new 3 to 4 year old and 7 to 11 year old patients attending the general paediatric, medical, and surgical outpatient clinics at the Queen Elizabeth Hospital for Children were studied on two mornings per week. The general paediatric medical and surgical outpatient clinics serve the district and the North East Thames Health Region. Patients with hernia, undescended testes, and gastroenterological problems were typical of those attending the surgical outpatient clinic, and respiratory tract infections, failure to thrive, epilepsy, and asthma were typical disorders presenting to the medical outpatient clinic.

The mothers were approached immediately after they had had their consultation with the paediatric surgeon or paediatrician. Mothers of the 7 to 11 year old children were asked to complete the Wakefield self assessment depression inventory, ${ }^{8}$ and the Rutter $\mathrm{A}_{2}$ scale. $^{1}$

The Wakefield self assessment depression inventory has been evaluated using a group of 'normal' employees of a hospital and a group of patients. The 
overall score for the female employees was 6.72 and for the female patients 24.72 .

When a score of 14 to 15 was used as a cut off, the difference between patients and 'normal' employees was highly significant. ${ }^{8}$ This was the cut off point used in our study. The scale consists of 12 statements with four possible answers to each statement for example 'I feel miserable and sad'. The mother could answer: (a) yes definitely, (b) yes sometimes, (c) no not much, and (d) no not at all. The Rutter $\mathrm{A}_{2}$ scale (parents) consists of 31 questions and statements on the child's health, habits, and behaviour. The following statement is an example: 'is often disobedient'. The mother could give one of three possible responses: (a) does not apply, (b) applies somewhat, and (c) certainly applies. A cut off point of 13 on this scale was found to be the best discriminator between patients attending a child psychiatric department and others ${ }^{1}$ and this was the cut off point used in the present study to measure behavioural deviance.

The behavioural screening questionnaire ${ }^{9}$ was completed in an interview with mothers of children aged 3 to 4 years. It consists of 12 questions on feeding, toilet training, tantrums etc. The interviewer rates mother's responses on a three point scale depending on severity. The inter-rater reliability for this scale is satisfactory $(r=0 \cdot 94)$. A cut off point of 10 has been found to be most satisfactory for identifying children with behavioural deviance ${ }^{9}$ and was used in this study.

Each mother was asked to give permission for the Rutter $B_{2}$ scale $^{1}$ (teachers) to be sent to the school for completion. Teachers were also asked to complete a second Rutter $B_{2}$ scale for the next child of the same age and sex in the same class register. This second child was a classroom control. The Rutter $\mathrm{B}_{2}$ scale consists of 26 statements, for example 'bullies other children', and allows the teacher to score: (i) does not apply, (ii) applies somewhat, and (iii) certainly applies. The inter-rater reliability is satisfactory $(r=0 \cdot 72)$. The Rutter $B_{2}$ scale has been shown to discriminate satisfactorily between children attending a psychiatric outpatient clinic and others.

\section{Results}

Forty mothers of children aged 7 to 11 years were approached at the surgical outpatient clinic and 36 completed the questionnaires. Sixty two mothers of children aged 7 to 11 years were approached in the medical sample, and 59 completed the questionnaires. All 20 mothers of children aged 3 to 4 years attending the medical outpatient clinic who were asked to do so completed the questionnaires.
Twenty three of 24 mothers with children aged 3 to 4 years attending the surgical outpatient clinic completed the questionnaires. All the teachers requested to fill out the teacher's questionnaire on the 7 to 11 year old age group and on the controls completed them.

(1) Teacher's questionnaires. ${ }^{10}$ (a) Surgical: As judged by scores on the teacher's questionnaires the rate of deviance in the surgical outpatient sample was over twice that in the control group, that is surgical outpatients $44 \%$ and control $19 \%(P<0.05)$. (b) Medical: In the medical outpatients' sample the rate of deviance on the teacher's questionnaire was exactly similar for patients and controls, that is $25 \%$ in both cases. There was a considerably greater amount of behavioural deviance in the surgical sample $(44 \%)$ compared with the medical sample (25\%) $\mathrm{P}<0 \cdot 1$. (See Table 1).

(2) Parental questionnaires. ${ }^{1}$ The rate of behavioural deviance in the 7 to 11 year old children in the surgical sample was 16 of $36(44 \%)$ and 22 of 59 $(37 \%)$. The difference between the two samples did not achieve statistical significance $\left(\chi^{2}=0 \cdot 23\right)$.

(3) Behavioural screening questionnaire. ${ }^{9}$ The number of 3 to 4 year old children in the medical sample with behavioural problems was 11 of $22(50 \%)$ and 9 of $23(39 \%)$ in the surgical sample. The difference between the two samples was not statistically significant $\left(\chi^{2}=0 \cdot 19\right)$.

(4) Wakefield self-assessment depression inventory. ${ }^{\gamma}$ There were nearly three times as many mothers with depressive symptoms in the medical sample of 3 to 4 year olds compared with mothers in the surgical sample in the same age group but this difference was not statistically significant $\left(\chi^{2}=1 \cdot 19\right)$. There was also no significant difference between the mothers with depressive symptoms in the paediatric medical 7 to 11 year old sample and the mothers of the paediatric surgical 7 to 11 year olds. $\left(\chi^{2}=1 \cdot 59\right)$. (See Table 2$)$.

Table 1 Teacher's questionnaire (Rutter $B_{2}$ scale): proportion of children with deviant scores

\begin{tabular}{lll}
\hline & $\begin{array}{l}\text { Total deviant } \\
\text { scores }(\%)\end{array}$ & $\begin{array}{l}\text { No and sex of those } \\
\text { with deviant score }\end{array}$ \\
\hline $\begin{array}{l}\text { Surgical outpatient clinic } \\
\quad(n=36)\end{array}$ & 44 & $7 F 9 M$ \\
Surgical controls $(n=36)$ & 19 & $3 F$ M \\
Medical outpatient $(n=59)$ & 25 & $5 F 10 M$ \\
Medical controls $(n=59)$ & 25 & $6 F 9 M$
\end{tabular}


Table 2 Wakfield self assessment depression inventory: number of mothers with deviant scores

\begin{tabular}{lcc}
\hline & $\begin{array}{l}\text { Mothers with } \\
\text { deviant scores } \\
(\%)\end{array}$ & $\begin{array}{l}\text { Total } \\
\text { no }\end{array}$ \\
\hline Surgical outpatients (3-4 year olds) & 9 & 23 \\
Surgical outpatients (7-11 year olds) & 17 & 36 \\
Medical outpatients (3-4 year olds) & 31 & 22 \\
Medical outpatients (7-11 year olds) & 32 & 22 \\
\hline
\end{tabular}

\section{Discussions}

The hypothesis that there was more behavioural deviance in the medical and surgical paediatric outpatients than in the general population has been borne out except in the medical outpatient sample of 7 to 11 year olds. The reason this group did not show a greater rate of deviance may have been the number of refusals to complete the questionnaire. This refusal rate may have led to an under estimate of pathology in this group. The reliability of the behavioural deviance found in the classroom controls is supported by the fact that the rates found were exactly similar $(19 \%)$ to those found in a much larger study using the same questionnaire in a similar population, ${ }^{4}$ even though asking the teacher to complete the next child of the same age and sex in the same class register may have allowed some teachers to choose other than the subsequent child. The 7 to 11 year old children attending the paediatric surgical outpatient clinic showed over twice the rate of behavioural deviance as has been shown in a general population sample using the same questionnaire. ${ }^{4}$ The high rates of behavioural deviance were again shown in the 3 to 4 year old sample attending the medical outpatient clinic where the rate was twice that found in a random sample of a similar age group. ${ }^{29}$

The second hypothesis that there would be more depressive symptoms in mothers of children attending the medical outpatient clinic compared with the surgical outpatient clinic was not substantiated. Nevertheless, there was evidence $(32 \%$ in mothers of 7 to 11 year old sample) of considerable depressive symptoms in those mothers who brought their children to the clinic. (See Table 2.) It is possible that maternal depression makes the mother less sensitive and less available emotionally to the child. The depression could, therefore, undermine the mother's parenting ability, which might result in the child developing behavioural problems. Clinical experience suggests this mechanism, but it requires further study.

The findings in the mothers and children raise the possibility that the reason for consultation in some cases where no physical disorder is found may be the mother's depression or behavioural deviance in the child. It has been shown in the past that the mothers who brought their children to a child guidance clinic were more apt to be anxious and depressed. ${ }^{11}$

The findings are of importance to paediatricians. They suggest that brief psychological assessments of mother and child should be carried out during outpatient consultations. They also suggest that paediatric registrars should have special training in carrying out these assessments in departments of child psychiatry. This study also emphasises the need for close working relationships between paediatricians and child psychiatrists.

I thank Dr C Dennihy, Dr E Taylor, Miss V Wright, Dr J Laurence, and Mr T Kinsella for their help and support. MF was supported by a grant from the Joint Research Board of the Hospital for Sick Children, London.

\section{References}

${ }^{1}$ Rutter M, Tizard J, Whitmore K. Education, health and behaviour. London: Longman. 1970.

2 Richman N, Stevenson JE, Graham PJ. Prevalence of behavioural problems in 3 year old children. An epidemiological study in a London borough. J Child Psychol Pyschiatry 1975;16: 277-87.

${ }^{3}$ Rutter M. Why are London children so disturbed? Proceedings of the Royal Society of Medicine 1973;66:1221-5.

4 Rutter M, Cox A, Tupling C, Berger M, Yule W. Attainment and adjustment in two geographical areas. 1. The prevalence of psychiatric disorder. Br J Psychiatry 1975;126:493-509.

5 Goldberg ID, Regier DA, McInerny TK, Pless IB, Roghmann KJ. The role of the paediatrician in the delivery of mental health services to children. Pediatrics 1979;63:898-909.

6 Apley J. The child with abdominal pains. 2nd ed. Oxford: Blackwell Scientific Publications, 1975.

${ }^{7}$ Howells JG. Modern perspectives in child psychiatry. Edinburgh: Oliver and Boyd, 1965.

${ }^{8}$ Snaith RP. Assessment of the severity of primary depressive illness. Psychol Med 1971;1:143-9.

9 Richman N, Graham PJ. A behavioural screening questionnaire for use with 3 year old children. Preliminary findings. J Child Psychol Psychiatry 1971;12:5-33.

10 Rutter M. A children's behaviour scale for completion by teachers. Preliminary findings. J Child Psychol Psychiatry 1973;8:1-11.

1 Shepherd M, Oppenheim AN, Mitchell S. Childhood behaviour disorder and the child guidance clinic. An epidemiological study. J Child Psychol Psychiatry 1966;7:39-52.

Correspondence to $\mathrm{Dr} M$ Fitzgerald, Ballyfermote Child and Family Centre, Dublin 10.

Received 14 February 1985 